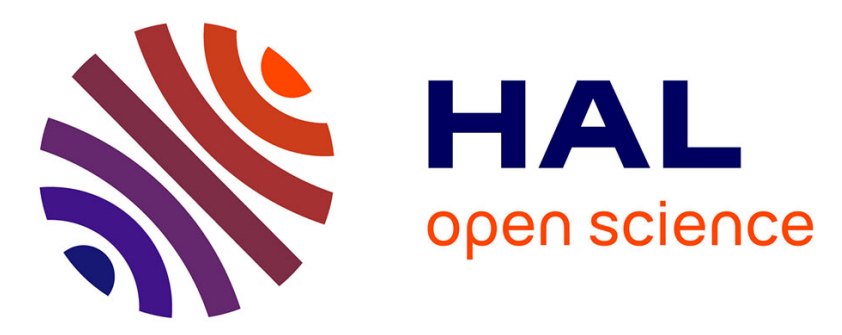

\title{
A quantum chemistry evaluation of the stereochemical activity of the lone pair in PbII complexes with sequestering ligands
}

\author{
A. Moncomble, J.P. Cornard, M. Meyer
}

\section{- To cite this version:}

A. Moncomble, J.P. Cornard, M. Meyer. A quantum chemistry evaluation of the stereochemical activity of the lone pair in $\mathrm{PbII}$ complexes with sequestering ligands. Journal of Molecular Modeling, 2017, 23 (1), pp.24. 10.1007/s00894-016-3190-y . hal-01505428

\author{
HAL Id: hal-01505428 \\ https://hal.science/hal-01505428
}

Submitted on 17 Dec 2021

HAL is a multi-disciplinary open access archive for the deposit and dissemination of scientific research documents, whether they are published or not. The documents may come from teaching and research institutions in France or abroad, or from public or private research centers.
L'archive ouverte pluridisciplinaire HAL, est destinée au dépôt et à la diffusion de documents scientifiques de niveau recherche, publiés ou non, émanant des établissements d'enseignement et de recherche français ou étrangers, des laboratoires publics ou privés. 


\title{
A quantum chemistry evaluation of the stereochemical activity of the lone pair in $\mathbf{P b}^{\mathrm{II}}$ complexes with sequestering ligands
}

\author{
Aurélien Moncomble, ${ }^{1 *}$ Jean-Paul Cornard, ${ }^{1}$ Michel Meyer ${ }^{2}$ \\ 1. Univ. Lille, CNRS, UMR 8516 - LASIR - Laboratoire de Spectrochimie Infrarouge et Raman, F- \\ 59000 Lille, France \\ 2. Institut de Chimie Moléculaire de l'Université de Bourgogne (ICMUB), UMR 6302, CNRS, \\ Université de Bourgogne-Franche-Comté, 9 avenue Alain Savary, BP 47870, 21078 Dijon Cedex, \\ France
}

*AM: aurelien.moncomble@univ-lille1.fr; +33 320434914

\begin{abstract}
The stereochemical activity of the lone pair on $\mathrm{Pb}^{\mathrm{II}}$ complexes is assessed using several theoretical methods, including structural analyses, computations of Fukui functions, natural bond orbitals, electron localization function, investigation of the electron density and of its laplacian. The attention is focused on four octadentate $N$-carbamoylmethyl-substituted tetraazamacrocycles of various ring sizes ranging from 8 to 14 atoms associated with the $\mathrm{Pb}^{\mathrm{II}}$ cation. The theoretical study illustrates the geometrical constraints imposed by the ring structure which limits the spatial development of the lone pair but without fully preventing it. For a given coordination number, the lone pair activity is strongly correlated to the geometry of the ligand and in particular to the size of the cage that the ligand forms around the $\mathrm{Pb}^{\mathrm{II}}$ cation. Some limitations of the theoretical tools used are also evidenced, among them the necessity to sample around a critical point instead of just analyzing its nature. In the case of the laplacian of the electron density, a visualization method is introduced to moderate the results based only on the nature of a critical point. These limitations should also be related to the difficulty to extend the lone pair concept for the heaviest atoms of the classification.
\end{abstract}

\section{Keywords}

Lead complexes; Lone Pair; DFT; AIM; Laplacian; NBO

\section{Acknowledgments}


This work was granted access to the HPC resources of CINES (Centre Informatique National de l'Enseignement Supérieur) and IDRIS (Institut du Développement et des Ressources en Informatique Scientifique) under the allocations 2015086933 and 2016086933 made by GENCI (Grand Equipement National de Calcul Intensif). Financial supports from the Centre National de la Recherche Scientifique (CNRS) and the Conseil Régional de Bourgogne (PARI II-CDEA program) are gratefully acknowledged. 


\section{Introduction}

The solution chemistry of $\mathrm{Pb}^{\mathrm{II}}$ cations is a debate that is still open after decades of investigations, due to the fact that usual methods such as neutron or X-ray scattering are difficult to apply to this highly-absorbing element [1]. Three main geometries around the $\mathrm{Pb}^{\mathrm{II}}$ cation are known, which are classically referred to as holodirected, hemidirected [2] and bisdirected (Figure 1) [3]. The holodirected case concerns situations where an approximate spherical symmetry is observed around the cation. The hemidirected arrangement describes complexes in which all donor atoms belonging to the ligands are located in the same hemisphere, while the stereochemically active lone pair occupies the opposite hemisphere. Such an asymmetric environment might also be encountered in some organometallic compounds or complexes incorporating $\mathrm{Sn}^{\mathrm{II}}$ centers, as tin is located just above lead in the periodic classification [1]. Finally, the bisdirected case is related to situations where the lone pair is split in two parts by a plane. The physical origin of these variety of geometries is related to the so-called inert-pair effect. Indeed, the $\mathrm{Pb}^{\mathrm{II}}$ cation possesses a $6 \mathrm{~s}^{2}$ pair of electrons which is contracted owing to relativistic effects and therefore is scarcely involved in the formation of bonds $[4,5]$. It can therefore be considered as a lone pair. From a stereochemical point of view, this lone pair can be either stereochemically active, as a consequence of the hybridization of the 6s orbital with the unoccupied 6p orbitals, or inactive according to the Valence Shell Electron Pair Repulsion (VSEPR) formalism. Although not fully understood yet, it is commonly admitted that the activity of this electronic pair depends, among other factors, on the nature of the donor atoms bound to the $\mathrm{Pb}^{\mathrm{II}}$ cation and on its coordination number (CN) [2, 6]. For values of CN below 5, the geometry around lead should be hemidirected while for values above 9, the holodirected geometry is encountered. $\mathrm{CN}$ values comprised between 6 and 8 are on the frontier and no a priori conclusion should be drawn. The bisdirected situation appears to be mostly found with planar and symmetrical ligands [7].

The geometry around the $\mathrm{Pb}^{\mathrm{II}}$ cation in a complex is not easily predictable by quantum chemistry computations. The results are quite dependent of the basis set or the electron core potential used to describe lead [6], and dynamic simulations are often necessary to fully account for the geometry of the $\mathrm{Pb}^{\mathrm{II}}$ cation in aqueous solution [8, 9]. Several theoretical tools have been applied to obtain more insight into the electronic descriptions of these complexes, such as ELF (Electron Localization Function) and NBO (Natural Bond Orbitals) analyses [7, 10].

In this context, it appears interesting to consider polydentate ligands that act like sequestering agents towards the $\mathrm{Pb}^{\mathrm{II}}$ cation. Indeed, for a same $\mathrm{CN}$, the situation with a $n$-dentate ligand and the one with $n$ monodentate ligands are not equivalent because of severe geometrical constraints 
imposed by the $n$-dendate backbone. In that respect, the $\mathrm{Pb}^{\mathrm{II}}$ cation uptake by macrocyclic ligands has been the subject of numerous studies for more than two decades. We focus herein on two tetraazamacrocyclic ligands appended with four coordinating acetamide arms (Figure 2), namely the 1,4,8,11-tetrakis(carbamoylmethyl)-1,4,8,11-tetraazacyclotetradecane [11] (TETAM, 14-membered, denoted as $\underline{\mathbf{L 1}}$ ) and the 1,4,7,10-tetrakis(carbamoylmethyl)-1,4,7,10-tetraazacyclododecane [12] (DOTAM, 12-membered, denoted as $\underline{\mathbf{L 2}}$ ). These octadentate sequestering agents are prone to encapsulate various metal cations, including earth-alkalines, transition metals and lanthanides [1318], but also main group elements such as the $\mathrm{Pb}^{\mathrm{II}}$ cation [19-22]. Derivatives of the 14-membered ligand TETAM (L1) have found interesting applications as solid/liquid extracting agents once grafted on silica gel $[11,23]$ or for the voltammetric quantification of lead using carbon paste electrodes [22] Structural studies by X-ray diffraction support a holodirected layout of the $\mathrm{N}_{4} \mathrm{O}_{4}$ donor set in $[\mathrm{Pb}(\underline{\mathbf{L 1}})]^{2+}$. The cyclen-based 12-membered macrocycle DOTAM ( $\left.\underline{\mathbf{L 2}}\right)$ forms likewise an encaged complex of $[\mathrm{Pb}(\underline{\mathbf{L 2}})]^{2+}$ formula, albeit of much higher stability [24]. In spite of the similarity of both $[\mathrm{Pb}(\underline{\mathbf{L} 1})]^{2+}$ and $[\mathrm{Pb}(\underline{\mathbf{L} 2})]^{2+}$ structures, the $\mathrm{Pb}^{\mathrm{II}}$ cation, which sits in between both $\mathrm{N}_{4}$ and $\mathrm{O}_{4}$ mean planes, penetrates more deeply into the cavity of $\underline{\mathbf{L} \mathbf{1}}$ than of $\underline{\mathbf{L 2}}$. This might be ascribed to the smaller ring size of the cyclen moiety of $\underline{\mathbf{L} 2}$, which results in a less pronounced folding of the acetamide arms over the cavity. Indeed, a small void is found between the oxygen atoms in $[\mathrm{Pb}(\underline{\mathbf{L} 2})]^{2+}$, that could be linked to the development of the stereochemical activity of the $6 \mathrm{~s}^{2}$ lone pair, but it is still a matter of debate. To explain this link, some authors reported in 2004 the crystal structure of the $[\mathrm{Pb}(\underline{\mathbf{L} 2})]\left(\mathrm{ClO}_{4}\right)_{2} \bullet 4.5 \mathrm{H}_{2} \mathrm{O}$ complex that contains two independent but similar $[\mathrm{Pb}(\underline{\mathbf{L 2}})]^{2+}$ cations [19]. One has a water molecule placed $3.52 \AA$ away from the lead center above the mean $\mathrm{O}_{4}$ plane, while in the other an amide nitrogen atom is in the same position at a distance of $4.1 \AA$. Based on these observations and on the presence of a void in the oxygen coordination calotte, these authors concluded that the lone pair is stereoactive and located on the $\mathrm{Pb}-\mathrm{O}_{\text {water }}$ or $\mathrm{Pb}-\mathrm{N}$ amide fourfold rotation $\left(C_{4}\right)$ symmetry axis. A few years later, other authors argued that the void in the coordination sphere of $[\mathrm{Pb}(\underline{\mathbf{L} 2})]\left(\mathrm{NO}_{3}\right)_{2} \cdot 3.5 \mathrm{H}_{2} \mathrm{O}$ could be more likely explained in terms of Van der Waals contacts $\left(d(\mathrm{O} \cdots \mathrm{O})=3.65(9) \AA\right.$ while $\left.2 R_{\mathrm{Vdw}}(\mathrm{O})=3.04 \AA\right)$ and steric repulsion between oxygen atoms rather than to the intrinsic electronic properties of the $6 \mathrm{~s}^{2}$ lone pair, and thus ruled out its stereochemical activity [21]. Their reasoning relied on the virtual absence of a void in the oxygen calotte but also of an exogenous ligand like a water molecule above the lead center. Considering that both crystal structures are superimposable with RMSD differences below $0.17 \AA$, the occurrence of an exogenous water molecule or an amidic nitrogen atom along the $C_{4}$ axis has no influence on the positioning of the carbamoyl oxygen atoms and therefore their presence cannot be viewed as criterion for assessing the activity of the lone pair. Moreover, similar $\mathrm{Pb}-\mathrm{O}$ and $\mathrm{Pb}-\mathrm{N}$ 
distances were found, which are typical for inactive lead compounds, whereas an active lone pair would require shorter $\mathrm{Pb}-\mathrm{L}$ distances in the hemisphere opposite to the lone pair, where $\mathrm{L}$ stands for any donor atom [19]. In 2015, a thorough study was devoted to the $\mathrm{Pb}^{\mathrm{II}}$ complex of DOTA ${ }^{4-}$, the tetracarboxylate analog of $\underline{\mathbf{L} 2}$ [25]. Relying on a wide range of techniques (UV-vis measurements, DFT computations, X-ray diffraction data), these authors suggested a possible activity of the lone pair, although the classically invoked bond-distance arguments have to be taken with caution owing to the geometrical constraints enforced by the macrocycle. Moreover, the charge difference between the neutral $\underline{\mathbf{L} 2}$ ligand and its tetraanionic DOTA ${ }^{4-}$ carboxylic counterpart prevents from drawing definitive conclusions about the hybridization status in $[\mathrm{Pb}(\underline{\mathbf{L} 2})]^{2+}$.

In an attempt to provide an additional insight, we have investigated by several up-to-date theoretical methods the electronic features of the $\mathrm{Pb}^{\mathrm{II}}$ cation in complexes formed with $\underline{\mathbf{L} \mathbf{1}}$ and $\underline{\mathbf{L} \mathbf{2}}$ but also with two hitherto unknown macrocyclic ligands incorporating either a 10- $(\underline{\mathbf{L} 3})$ or an 8-membered $(\underline{\mathbf{L} 4})$ tetraamine in order to gauge the impact of the ring size on the activity of the lone pair. In addition, the lead complex of the hexadentate open-chain chelator $N, N, N^{\prime}, N^{\prime}$ tetra(carbamoylmethyl)ethylenediamine ( $\underline{\mathbf{L} 5}$ ) was also considered for comparison purposes, as this tetraacetamide version of EDTA $^{4-}$ generates a hemidirected distribution of the donor atoms around lead with an undisputable activity of the lone pair [26]. The comparison of the five corresponding $\mathrm{Pb}^{\mathrm{II}}$ complexes affords a homogeneous series with two touchstones: $[\mathrm{Pb}(\underline{\mathbf{L} \mathbf{1}})]^{2+}$ evidences a holodirected environment around the $\mathrm{Pb}^{\mathrm{II}}$ cation, while $[\mathrm{Pb}(\underline{\mathbf{L} 5})]^{2+}$ shows a hemidirected one, that will allow a classification of the three others, especially $[\mathrm{Pb}(\underline{\mathbf{L} 2})]^{2+}$. Methods considered in this study include structural analyses based on single geometries obtained by a static approach, ELF and NBO studies, analyses of the electron density and of its laplacian. The comparison of electronic properties circumvents the aforementioned limitations inherent to the interpretation of absolute values computed for a single species by quantum chemical tools. 


\section{Computational methods}

All the calculations were carried out using the Gaussian 09 series of programs [27]. Energies were computed using Density Functional Theory (DFT) based methods, namely the PBE0 global hybrid functional [28, 29]. Optimizations were carried out using default algorithms of Gaussian, and followed by subsequent vibrational analysis. For existing complexes, the X-ray structures encountered in previously mentioned references were used as starting points. For optimizations, lead atom was described using the Def2-TZVPD basis set and the associated electron core potential (ECP that includes 28 electrons) [30], while other atoms were described using the $6-311+\mathrm{G}^{* *}$ basis set [31]. The solvent, water, was taken into account using the Polarized Continuum Model (PCM) implicit formalism as implemented in Gaussian [32].

Due to the size of the ligands, the effect of the dispersion on the geometrical parameters was evaluated by adding it using the D3 empirical formalism [33]. The optimization was carried out for $[\mathrm{Pb}(\underline{\mathbf{L 1}})]^{2+}$ and a comparison of the structures by the means of a RMSD calculation (Root Mean Square Deviation) using the Kabsch algorithm. A value of $4.2 \mathrm{pm}$ (3.5 pm if the hydrogen atoms are not taken into account) was obtained, thus confirming the very low influence of the dispersion, which was hereafter neglected.

For electron density analysis, the optimization was followed by a single point computation for which the ECP and basis set used to describe lead atom were replaced by the WTBS all-electron basis set [34] to prevent the apparition of spurious non-nuclear attractors (the other atoms were still described by the $6-311+G(d, p)$ basis set).

The natural bond orbitals (NBO) studies were carried out using the NBO 3 facilities included in Gaussian [35], the topology of the electron density and its laplacian studies (atom in molecules (AIM) study) required the use of AIMAll 14.06.21 program [36], while the electron localization function (ELF) computation was processed using the TopMod 09 software [37].

To test the influence of relativistic effects on the computed properties, single points computations using the Douglas-Kroll-Hess $2^{\text {nd }}$ order scalar relativistic Hamiltonian [38] were processed on the previously optimized geometry for $[\mathrm{Pb}(\underline{\underline{\mathbf{L 1}}})]^{2+}$, using a point nuclei model and the DZP-DKH basis set. The differences in the electron density between the relativistic and non-relativistic computations around the critical points were too small to influence their nature so this effect was not taken into account in the following for the different complexes. 


\section{Results and discussion}

To assess the stereochemical activity of the lone pair localized on the $\mathrm{Pb}^{\mathrm{II}}$ cation for each complex, some indicators were inspected to make a difference between the complexes formed with the five studied ligands. These indicators belong to three different categories: structural indicators, orbitalbased indicators and density-based indicators (including ELF). To discriminate between the complexes, an indicator is computed for each complex and a gap between values is expected. If the variation is too smooth, the indicator is not conclusive. Otherwise, a tentative conclusion can be drawn.

\subsection{Structure-based indicators}

After optimizing the geometry of each of the five studied complexes, some structural parameters were compared as a first approach to check for the presence of an active lone pair on the $\mathrm{Pb}^{\mathrm{II}} \mathrm{cation}$ The symmetry was not enforced during the optimization so the reported point-group symmetries are not perfectly rigorous but are the closest from the computed geometry. Two views of the optimized geometry of $[\mathrm{Pb}(\underline{\mathbf{L} 2})]^{2+}$ are depicted on Figure 3a (side view) and 3b (top view). The most significant structural parameters are reported in Table 1. Among the reported parameters, the relative height $h_{\mathrm{r}}$ needs some explanation. It is defined by equation (1) where $d_{\mathrm{N}}$ and $d_{\mathrm{O}}$ are the distances between the $\mathrm{Pb}^{\mathrm{II}}$ cation and the mean planes passing through the four bound nitrogen and oxygen atoms, respectively.

$$
h_{r}=\frac{d_{N}}{d_{N}+d_{O}}
$$

It is a normalized mean to measure the position of the $\mathrm{Pb}^{\mathrm{II}}$ cation in the molecular cage delimited by the tetraamine on one side and the amide groups bent over the macrocycle on the opposite side, independently from the ring size. A value of 0 or 1 corresponds to a perfect embedding of the metal cation in the mean plane of the four nitrogen or oxygen atoms, respectively, while values inbetween indicate intermediate positions. Other relevant parameters describing the pseudo-twisted square antiprismatic coordination polyhedron are $\varphi$ (bite angle of the ligand) and $\Omega$ (solid angle under which the polygon defined by the four binding oxygens is seen from the $\mathrm{Pb}^{\mathrm{II}}$ cation) (Figure 3c).

Three complexes, namely $\left[\mathrm{Pb}(\underline{\mathbf{L} 1)}]^{2+}[23],[\mathrm{Pb}(\underline{\mathbf{L} 2})]^{2+}[21]\right.$ and $[\mathrm{Pb}(\underline{\mathbf{L}} \mathbf{5})]^{2+}[26]$, offer the opportunity to compare the calculated structures with the crystallographic ones, even if this comparison must be carried out with precautions due to the difference between the physical states of the studied 
compounds. In all cases, $\mathrm{Pb}-\mathrm{N}$ distances predicted by DFT computations are longer (by 0.05 to 0.12 $\AA$ ) than experimental ones, as stressed recently in a related study of [Pb(DOTA) $]^{2-}$ [25], whereas $\mathrm{Pb}-\mathrm{O}$ distances are reproduced more accurately (within $0.02 \AA$ or better). Nevertheless, it is rather gratifying to note that the computed and experimental distances are overall in excellent agreement (Table 1). In particular, $\mathrm{Pb}-\mathrm{N}$ bonds shorter than $\mathrm{Pb}-\mathrm{O}$ ones are predicted for $[\mathrm{Pb}(\underline{\mathbf{L} 2})]^{2+}$ and $[\mathrm{Pb}(\underline{\mathbf{L} 5})]^{2+}$, whereas the situation is reversed for $[\mathrm{Pb}(\underline{\mathbf{L 1}})]^{2+}$. The same trend is also evidenced by the crystal structures. The stereochemistry of the complexes has been taken into account. Indeed, cyclen-derived ligands bearing four binding groups like $\underline{\mathbf{L} 2}$ afford chiral inclusion complexes. The chirality is associated to ( $i$ ) the layout of the four coordinated arms arranged around the metal in a propeller-like fashion (noted $\Delta$ for a right-handed or $\Lambda$ for a left-handed orientation) and (ii) the conformation of the cyclen fragment, each of the four M,N,C,C,N chelate rings adopting either a $\delta$ or $\lambda$ helicity. Hence, four possible stereoisomers for $[\mathrm{Pb}(\underline{\mathbf{L} 2})]^{2+}$ are conceivable, which divide into two diastereoisomeric pairs of enantiomers, denoted $\Delta-(\delta, \delta, \delta, \delta) / \Lambda-(\lambda, \lambda, \lambda, \lambda)$ and $\Delta-(\lambda, \lambda, \lambda, \lambda) / \Lambda$ $(\delta, \delta, \delta, \delta)$, respectively. The homochiral arrangement around the metal center affords a distorted inversed or twisted square antiprism (TSAP), while the heterochiral pair of enantiomers favors a square antiprismatic (SAP) coordination polyhedron of ideal $C_{4}$ symmetry [17]. The DFT optimized structures correspond to the $\Delta-(\delta, \delta, \delta, \delta)$ diastereoisomer of TSAP geometry, which is the one identified by X-ray crystallography [19, 21].

More useful is the examination of the distances from the $\mathrm{Pb}^{\mathrm{II}}$ cation to the mean plane defined by the bound oxygen and nitrogen atoms and, more specifically, to $h_{\mathrm{r}}$. A clear increase of this value is obtained from $\underline{\mathbf{L} \mathbf{1}}$ to $\underline{\mathbf{L}}$, that means that the cation is progressively released by the ligand cage till $\underline{\mathbf{L} 5}$ where it stands mostly outside of the ligand, suggesting the progressive appearance of an active lone pair. Interestingly, the $h_{\mathrm{r}}$ values correlate with two associated geometrical parameters: the bite angle $\varphi$ and the solid angle $\Omega$. The latter parameter is a direct measure of the void between the bound oxygen atoms, which amounts $24 \%$ of the space around the $\mathrm{Pb}^{\mathrm{II}}$ cation in the case of $[\mathrm{Pb}(\underline{\mathbf{L} 1})]^{2+}$ up to $58 \%$ in the case of $[\mathrm{Pb}(\underline{\mathbf{L} 5})]^{2+}$. Since a value of $17 \%$ is expected for a perfectly cubic symmetry around the $\mathrm{Pb}^{\mathrm{II}}$ cation (that is unreachable with such polydentate ligands), this parameter supports a holodirected layout of $\underline{\mathbf{L} \mathbf{1}}$ and the concomitant stereochemical inactivity of the $6 \mathrm{~s}^{2}$ pair in the corresponding complex.

The evolution of the three parameters $h_{\mathrm{r}}, \varphi$ and $\Omega$ reflects an opening of the ligand cavity and a release of $\mathrm{Pb}^{\mathrm{II}}$ cation from $\underline{\mathbf{L} \mathbf{1}}$ to $\underline{\mathbf{L} 5}$, the widening of the void between the oxygen atoms resulting in the development of an active lone pair. Although $[\mathrm{Pb}(\underline{\mathbf{L} 1})]^{2+}$ and $[\mathrm{Pb}(\underline{\mathbf{L} 2})]^{2+}$ exhibit similar values of $h_{\mathrm{r}}$, the $\Omega$ and $\varphi$ angles (232 vs. $219^{\circ}$ ) appear more differentiated. Then, a non-disputable cut-off value cannot be proposed as a reference to distinguish an active from an inactive lone pair from 
these geometrical indicators.

Moreover, it is interesting to focus on the very small variations of bond lengths with regards to the important variations of others geometrical parameters such as $\varphi$ or $h_{\mathrm{r}}$. These changes illustrate the low directionality of bonds between the donor atoms of the ligand and the $\mathrm{Pb}^{\mathrm{II}}$ cation that should be an argument in favor of the ionicity of the bond. This point will be studied in more details in next subsection.

Note that tentative optimizations with a water molecule added close to the potential lone pair of the $\mathrm{Pb}^{\mathrm{II}}$ cation, so as to reproduce the experimental observations with $[\mathrm{Pb}(\underline{\mathbf{L} 2})]^{2+}[19]$, were carried out for the five studied systems, but in each case, the formation of hydrogen bonds between the water molecules and the ligands oxygen atoms during geometry optimizations prevented convergence and to draw any conclusion on the possibility of an interaction between water and the $\mathrm{Pb}^{\mathrm{II}}$ cation. 


\subsection{Bonding in the $[\mathrm{Pb}(\underline{\mathrm{Ln}})]^{2+}$ complexes.}

One of the classical criterion to classify the activity of the lone pair is the ionicity of bonding, an ionic bonding is typically associated to a hemidirected environment, while a covalent bonding leads to a holodirected geometry [2]. Thus, this criterion was evaluated using both molecular orbitals and electron density.

\subsubsection{Orbital-based indicators}

Kohn-Sham (KS) molecular orbitals were first examined. The HOMO, representative of the lone pair on the $\mathrm{Pb}^{\mathrm{II}}$ cation, is the most meaningful and is depicted on Figure 4 for complexes with $\underline{\mathbf{L} \mathbf{1}}$, $\underline{\mathbf{L 2}}$, and $\underline{\mathbf{L} \mathbf{5}}$. A quasi-perfect spherical symmetry of the HOMO is obtained in the case of $[\mathrm{Pb}(\underline{\mathbf{L 1}})]^{2+}$ (Figure $4 \mathrm{a}$ ) while the stereochemical activity becomes clearly apparent in $[\mathrm{Pb}(\underline{\mathbf{L 5}})]^{2+}$ (Figure $4 \mathrm{c}$ ). The case of $[\mathrm{Pb}(\underline{\mathbf{L} 2})]^{2+}$ is, as expected, more ambiguous. A dissymmetry appears (ovoidal shape) but an activity is not obvious. The contribution of the ligand in these orbitals is similar whatever the ligand, and quite small, consistently with a prevailing ionic bonding in these complexes.

To analyze more precisely the nature of this lone pair, a NBO analysis was performed to provide a deeper insight into the hybridization of lead. In the five complexes, the last NBO with an occupation of nearly 2 electrons corresponds to the lone pair on the $\mathrm{Pb}^{\mathrm{II}}$ cation and the three following orbitals (by decreasing occupancy) are mostly the three $6 \mathrm{p}$ ones located on this atom. More details on the composition of these orbitals is provided in Table 2.

Conclusions that can be drawn from the electronic configurations contradict somehow those derived from purely structural considerations. According to Table 2, the contribution of the p orbitals to the

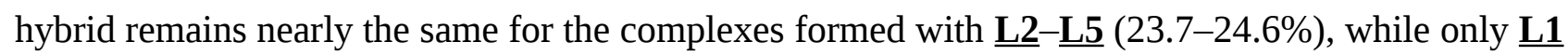
has a significant influence on the $\mathrm{Pb}^{\mathrm{II}}$ electronic configuration with a lower contribution (21.2\%) of p orbitals. As far as the lone pair is concerned, similar results were obtained: the largest gap in the series appearing again between $[\mathrm{Pb}(\underline{\mathbf{L} \mathbf{1}})]^{2+}(0.10 \%$ of $\mathrm{p}$ orbitals $)$ and $[\mathrm{Pb}(\underline{\mathbf{L} 2})]^{2+}(1.78 \%$ of $\mathrm{p}$ orbitals), although the $\mathrm{p}$ contribution to the lone pair increases regularly to reach $4.66 \%$ for $[\mathrm{Pb}(\underline{\mathbf{L} 5})]^{2+}$. Overall, these rather small percentages are consistent with those obtained in an earlier study devoted to $\mathrm{Pb}^{\mathrm{II}}$ complexes with small monodentate ligands [2]. Indeed, for anionic ligands, the computed values ranged from $0.00 \%\left(\right.$ in $\left[\mathrm{PbCl}_{4}\right]^{2-}$ ) to $15.72 \%$ (in $\left[\mathrm{Pb}(\mathrm{OH})_{4}\right]^{2-}$ ) and, for neutral ligands, from $0.50 \%$ (for $\left[\mathrm{Pb}(\mathrm{BrH})_{4}\right]^{2+}$ ) to $4.39 \%$ (for $\left[\mathrm{Pb}\left(\mathrm{NH}_{3}\right)_{4}\right]^{2+}$ ). The comparison of these values with those reported in Table 2 confirms unambiguously that an active lone pair is present when $\mathrm{Pb}^{\mathrm{II}}$ binds with $\underline{\mathbf{L} 5}$. In the previous study, typical values for hemidirected complexes are higher than $2 \%$ 
(the smallest for $\mathrm{O}$ and $\mathrm{N}$ ligands being 2.65\%). With these results in mind, complexes with $\underline{\mathbf{L} 3}$ and $\underline{\mathbf{L} 4}$ should also present an active pair, the complex with $\underline{\mathbf{L 1}}$ has indeed a holodirected environment, while the complex with $\underline{\mathbf{L} 2}$ stands near the frontier.

The composition of the three orbitals following the lone pair is predictable and fully consistent with our expectations: two of them are pure p orbitals while the other one is the complement of the lone pair, resulting from the interaction of the $6 \mathrm{~s}$ and a $6 \mathrm{p}$ orbital.

The second order energy terms representative of interactions between NBOs mainly located on $\mathrm{Pb}^{\mathrm{II}}$ vary with the same tendency, reflecting the most important interaction between s and p orbitals, and the hybridization of the lone pair. Here, a gap appears between $[\operatorname{Pb}(\underline{\mathbf{L} \mathbf{1}})]^{2+}$ and $[\mathrm{Pb}(\underline{\mathbf{L} 2})]^{2+}$, while the variation is less pronounced for the remaining complexes. Owing to the low involvement level of $p$ orbitals in the lone pair, $\Delta E$ does not vary along the series.

Among the others NBO, no orbitals involving both the $\mathrm{Pb}^{\mathrm{II}}$ cation and the ligand were obtained, whatever the ligand, illustrating the non-covalent nature of the interaction.

This subsection clearly pinpoints the difficulty to discriminate by the NBO approach active from inactive lone pairs in lead complexes. According the absolute contribution of the p orbitals in the lone pair composition, $\underline{\mathbf{L} 2}$ appears to induce the inactivity of the lone pair, while the opposite conclusion can be reached if the significant gap between all the other criteria computed for $[\mathrm{Pb}(\underline{\mathbf{L} 1})]^{2+}$ and $[\mathrm{Pb}(\underline{\mathbf{L} 2})]^{2+}$ are considered. Then, the percentage of $\mathrm{p}$ orbital in the NBO associated to the lone pair does not appear as a reliable criterion to discriminate a hemi- from a holodirected environment, although the examination of trends among a homogeneous series of complexes appears to be much more useful. 


\subsubsection{Electron density-based indicators}

An AIM study was performed by integrating electron density over Bader atoms. Critical points were localized and local or integrated properties were computed on bond critical points (BCPs) binding the $\mathrm{Pb}^{\mathrm{II}}$ cation and either nitrogen or oxygen atoms. Results are reported in Table 3. A BCP was always found between the nitrogen and oxygen atoms of the ligands and the $\mathrm{Pb}^{\mathrm{II}}$ cation. For $\underline{\mathbf{L} \mathbf{2}}$ and $\underline{\mathbf{L} 4}$ complexes, the symmetry was close enough to $C_{4}$ to give only one mean value for the four bonds of each kind. For $\underline{\mathbf{L} 1}, \underline{\mathbf{L} 3}$, and $\underline{\mathbf{L} 5}$ complexes, the obtained $C_{2}$ symmetry is too far from the $C_{4}$ one, so it was not meaningful to give a mean on the four bonds: two values are then given, one for each pair of $\mathrm{Pb}-\mathrm{O}$ and $\mathrm{Pb}-\mathrm{N}$ bonds.

Several criteria were computed, all implying a large ionic character of the metal-ligand bonds, although $\mathrm{Pb}-\mathrm{O}$ bonds were found slightly more ionic than $\mathrm{Pb}-\mathrm{N}$ ones. Firstly, the low electron density ( $\rho_{\mathrm{BCP}} \sim 0.03$ a.u.) and the positive values of the laplacian $\left(\nabla^{2} \rho_{\mathrm{BCP}} \sim 0.06-0.16\right.$ a.u.) are indicators of closed-shell interactions. These values are quite low due to the important length of the bond: in the case of the esculetin-lead complex [39], the density and its laplacian at the BCP were 0.074 a.u. and 0.369 a.u., respectively, with an average $\mathrm{Pb}-\mathrm{O}$ bond length is of $2.195 \AA$. The slightly negative value of the total electronic energy density $\left(H_{\mathrm{BCP}} \sim-0.0007\right.$ a.u. for $\mathrm{Pb}-\mathrm{O}$ and 0.002 a.u. for $\mathrm{Pb}-\mathrm{N}$ ) indicates a small dative character to these interactions [40]. Secondly, the opposite of the ratio between the kinetic electronic energy density and the potential electronic energy density computed at the BCPs are very close to 1 , indicating a predominantly ionic bond character with a very slight covalent contribution [41]. This result is enforced by the quite low value of the delocalization indexes ( $\left.\delta_{\mathrm{Pb}, \mathrm{N}} \sim \delta_{\mathrm{Pb}, \mathrm{O}} \sim 0.22\right)$, which are equal to 2 in the case of purely covalent binding.

Remarkably, examination of Table 3 reveals no significant differences among the five investigated complexes, all involving nearly identical $\mathrm{Pb}-\mathrm{O}$ and $\mathrm{Pb}-\mathrm{N}$ bond types. Whatever the computation scheme (AIM or NPA - natural population analysis), the partial charges on the oxygen and nitrogen atoms remain almost identical along the series (Table 4), while those on the $\mathrm{Pb}^{\mathrm{II}}$ cation vary in a somewhat erratic manner. Altogether, these results confirm the weak contribution of ligand orbitals in lead binding, as already pointed out in the preceding section devoted to the examination of the KS HOMOs. The ionic bond character evidenced herein is typically associated with a hemidirected environment and therefore to an active lone pair in all five complexes, which is in apparent contradiction with the structural features of $[\mathrm{Pb}(\underline{\mathbf{L} \mathbf{1}})]^{2+}$. Therefore, this criterion appears not to be discriminant in the case of these ligands which impose very strong geometrical constraints. 


\subsection{Lone pair localization}

The lone pair was more precisely located using three different methods. The use of Fukui functions, and the study of the topology of the ELF function and of the laplacian of the electron density around the $\mathrm{Pb}^{\mathrm{II}}$ cation were sought to provide three other kinds of indicators.

\subsubsection{Fukui functions}

The lone pair represents an excess of electron, associated to nucleophilicity. It is therefore logical to study the $f_{\mathrm{Pb}}$ function. The values of charges computed according to NPA and AIM schemes are reported in Table 4. From these values, condensed Fukui functions and the dual descriptor [42] on $\mathrm{Pb}^{\mathrm{II}}$ are computed by finite differences from single point calculations on the species charged $+1,+2$ and +3 using the geometry of the +2 species [43], according to equations (2) to (4), where $\rho$ is the electron density and $q_{i}(\mathrm{~Pb})$ the charge of the $\mathrm{Pb}^{\mathrm{II}}$ cation computed on the complex with the charge $i$.

$$
\begin{aligned}
f_{P b}^{+} & =\int_{P b} d \vec{r}\left(\frac{\partial \rho(\vec{r})}{\partial N}\right)_{v(\vec{r}), N \geq N_{0}}=q_{+2}(P b)-q_{+1}(P b) \\
f_{P b}^{-} & =\int_{P b} d \vec{r}\left(\frac{\partial \rho(\vec{r})}{\partial N}\right)_{v(\vec{r}), N \leq N_{0}}=q_{+3}(P b)-q_{+2}(P b) \\
f_{P b}^{(2)} & =\int_{P b} d \vec{r}\left(\frac{\partial^{2} \rho(\vec{r})}{\partial N^{2}}\right)_{v(\vec{r})} \approx f_{P b}^{+}-f_{P b}^{-}
\end{aligned}
$$

The results are reported in Table 4. The values of $f_{\mathrm{Pb}}^{+}$(electrophilicity of $\mathrm{Pb}$ ) and $f_{\mathrm{Pb}}$ (nucleophilicity of $\mathrm{Pb}$ ) are more significant than the charges. With a regular increase along the $[\mathrm{Pb}(\underline{\mathbf{L 1}})]^{2+}$ to $[\mathrm{Pb}(\underline{\mathbf{L} \mathbf{5}})]^{2+}$ series, the $f_{\mathrm{Pb}}$ evolution is especially striking, consistently with the progressive development of the activity of the lone pair. The electrophilicity is less relevant for this study and it appears less predictable: if $[\mathrm{Pb}(\underline{\mathbf{L} 5})]^{2+}$ is not taken into account, the $f^{+} \mathrm{Pb}$ values computed according to the NPA scheme decreases while those computed with the AIM scheme are not well correlated to the ring size, even if a general trend is obtained. Rejecting $\underline{\mathbf{L} \mathbf{5}}$ for the comparison of electrophilicity is quite reasonable: although this chelator possesses identical acetamide arms as the four others, it is only a hexadentate ligand, while the others ones are octadentate. This might influence the possible increase of the electron density on the ion.

The examination of $f^{(2)} \mathrm{Pb}$ turns out to be more interesting, as this parameter reflects the balance between the electrophilicity and the nucleophilicity of $\mathrm{Pb}$. For the same reason as for $f^{+} \mathrm{Pb}, \underline{\mathbf{L} \mathbf{5}}$ is not considered in this section. A decrease is computed from $\left[\mathrm{Pb}(\underline{\mathbf{L} 1)}]^{2+}\right.$ to $[\mathrm{Pb}(\underline{\mathbf{L} 4})]^{2+}$, a negative value (0.04 ) is even obtained for the latter complex with the AIM scheme (0.00 with the NPA scheme), 
pointing out the relative importance of the nucleophilicity. Two antagonist conclusions could be drawn from this examination: the values computed with the NPA scheme present a break between $[\mathrm{Pb}(\underline{\mathbf{L} 1})]^{2+}$ and $[\mathrm{Pb}(\underline{\mathbf{L} 2})]^{2+}$ while the evolution of $\mathrm{AIM}$ values is softer, precluding any clear-cut distinction between an active or inactive pair. Therefore, no clear conclusion should be given by this indicator. 


\subsubsection{ELF study}

The ELF function enables to localize free electron pairs in the space [44]. The topological study of this function leads to the identification of basins, linked to several atoms. Among the different possibilities, those linked to a single atom (monosynaptic basins) can be seen as lone pairs, while those linked to two atoms (disynaptic ones) are interpreted as bonding doublets. In this framework, we studied the existence and, if existent, the properties of the monosynaptic basin linked to the $\mathrm{Pb}^{\mathrm{II}}$ cation in the five complexes. Interestingly, such a basin was always localized and their properties are reported in Table 5. Its bifurcation point from the basins located on the binding atoms is obtained for an ELF value close to 0.15 for the five complexes. Values under 0.30 are often encountered in ionic compounds [45], that confirms the conclusion on the ionic character of bonds implying the $\mathrm{Pb}^{\mathrm{II}}$ cation.

A striking difference appears in the values of Table 5: the $[\mathrm{Pb}(\underline{\mathbf{L 1}})]^{2+}$ complex presents only a low developed monosynaptic basin (both considering the spatial extension and the population), while the four others ligands allow a more important development of a lone pair, with more expanded basins by at least a factor of 3, and a population staying close to 2 electrons. The same result is obtained by considering the maximum value of ELF on the monosynaptic basin on $\mathrm{Pb}^{\mathrm{II}}$. Indeed, this value is stationary for $[\mathrm{Pb}(\underline{\mathbf{L} 3})]^{2+}$ to $[\mathrm{Pb}(\underline{\mathbf{L} 5})]^{2+}$ (over 0.90$)$, lower for $[\mathrm{Pb}(\underline{\mathbf{L 2}})]^{2+}(0.82)$ and very low for $[\mathrm{Pb}(\underline{\mathbf{L} 1})]^{2+}(0.55)$.

Accordingly, the ELF analysis strongly supports a stereochemically inactive lone pair for the latter complex, in agreement with the holodirected environment of the eight donor atoms and the almost complete wrapping of the metallic center by $\underline{\mathbf{L} \mathbf{1}}$ that lefts only one fourth (24\%) of the solid angle around $\mathrm{Pb}^{\mathrm{II}}$ uncovered, but also with the almost isotropic distribution of the Kohn-Sham HOMO (Figure 4a). This would be a strong point in favor of a perfectly holodirected environment around $\mathrm{Pb}^{\mathrm{II}}$ in its complex with $\underline{\mathbf{L 1}}$ : a similar proportion of the lone pair (0.57 electrons out of 2 ) is in the monosynaptic basin of lead. This argument has to be used with precaution due to the important computed standard deviation (0.71 electrons). On the contrary, the population of the monosynaptic basin is about 2 in the four other cases, that could correspond to the presence of an active lone pair on lead, that is developed from $[\mathrm{Pb}(\underline{\mathbf{L 2}})]^{2+}$ to $[\mathrm{Pb}(\underline{\mathbf{L} 5})]^{2+}$ as illustrated by the progressive increase of its volume.

The ELF-based indicator evidences an important difference between the properties of $\underline{\mathbf{L} \mathbf{1}}$ and those of the four other ligands, that could qualify the environment around the $\mathrm{Pb}^{\mathrm{II}}$ cation as hemidirected in its complex with $\underline{\mathbf{L} 2}$. 


\subsubsection{Use of the laplacian of the electron density}

As for ELF, the study of the topology of the laplacian of the electron density localizes electron doublets [46]. Therefore, the results of this and the previous analyses should be close. Nevertheless, it is generally acknowledged that some features lacking in the ELF topology are recoverable from the laplacian study [47], that justifies the investigation of the selected series of complexes by both methodologies.

Consistently with the widespread usage, it is more precisely the opposite of the laplacian that is used in this subsection: $L(\mathbf{r})=-\nabla^{2} \rho(\mathbf{r})$. Then, the localization of points of charge concentration (depletion) that corresponds to minima (respectively maxima) of the laplacian of the electron density are associated to maxima (respectively minima) of $L(\mathbf{r})$. To follow the nomenclature of CPs used in the literature, they are given under the form of two numbers in parentheses: (total number of eigenvalues of the Hessian matrix, difference between the numbers of positive and negative eigenvalues). Accordingly, a maximum corresponds to the $(3,-3)$ notation.

Due to the symmetry of the considered systems, we focused on the nature of the critical point located on the $C_{\mathrm{n}}$ axis of rotation, in the void between the oxygen atoms. The nature of these CPs are $(3,+1)$ for $[\mathrm{Pb}(\underline{\mathbf{L 1}})]^{2+}$ and $[\mathrm{Pb}(\underline{\mathbf{L 2}})]^{2+},(3,-1)$ for $[\mathrm{Pb}(\underline{\mathbf{L} 3})]^{2+}$, and $(3,-3)$ for $[\mathrm{Pb}(\underline{\mathbf{L} 4})]^{2+}$ and $[\mathrm{Pb}(\underline{\mathbf{L} 5})]^{2+}$. Following these results, it should be assumed that a lone pair is present only in the lead complexes of $\underline{\mathbf{L} \mathbf{4}}$ and $\underline{\mathbf{L} \mathbf{5}}$ ligands, that present a maximum of $L(\mathbf{r})$ at the expected position for the lone pair. The location of this $\mathrm{CP}$ is depicted for $[\mathrm{Pb}(\underline{\mathbf{L} 4})]^{2+}$ on Figure 5.

Like any discrete parameter, the nature of the CP appears to be a too crude indicator. In order to smooth out the character of this indicator and to appreciate subtler changes occurring in the series of complexes, it seems important to investigate the topology of $L(\mathbf{r})$ not only at the CP but also in its vicinity. Hence, a standardized graphical representation was adopted to better compare the different complexes by sampling around the CPs. $L(\mathbf{r})$ values were collected for each complex at nine points (see Figure 5 for a self-explanatory localization of these points): (i) the CP along the $C_{n}$ axis discussed above (point A), (ii) the CPs closest to point $\mathrm{A}$ in the planes containing the oxygen and the lead atoms (points $\mathrm{B}_{i}$ with $i$ ranging from 1 to 4 ), and (iii) the CPs closest of the point $\mathrm{A}$ in the planes bisecting the planes defined in step ii (points $C_{i}$ with $i$ ranging from 1 to 4 ). Those nine values were then depicted on a graph at the coordinates referred on Figure 6a and interpolated by trigonometric functions. Although this choice of interpolating functions has no real physical meaning, it is consistent with the nature of each CP and provides an easier visualization of the local topology of the $L(\mathbf{r})$ function. No sampling point lying on the $C_{n}$ axis other than point A was considered, as this has no consequences for the comparison purpose because the point $\mathrm{A}$ is always a 
maximum in the $C_{n}$ axis direction. For each complex, the three-dimensional surface resulting from data interpolation can then be depicted in Figure 6 (panels (b) to (f)) by using the same scale.

The mesh graph representations of $L(\mathbf{r})$ smooths the crude classification given by the nature of the CP A. Indeed, the overall shape undergoes a continuous transition from a hollow surface for the holodirected $[\mathrm{Pb}(\underline{\mathbf{L} \mathbf{1}})]^{2+}$ species to a pronounced bumped profile for the hemidirected $[\mathrm{Pb}(\underline{\mathbf{L 5}})]^{2+}$ complex. It appears that the local topology obtained for $\left[\mathrm{Pb}(\underline{\mathbf{L} 4)}]^{2+}\right.$ and $[\mathrm{Pb}(\underline{\mathbf{L} 5})]^{2+}$ is a local maximum (Figures 6e and 6f), while the situation for $[\mathrm{Pb}(\underline{\mathbf{L} 2})]^{2+}$ and $[\mathrm{Pb}(\underline{\mathbf{L} 3})]^{2+}$ (Figures 6c and 6d) is not so distant.

The case of $[\mathrm{Pb}(\underline{\mathbf{L} 3})]^{2+}$ deserves some additional comments. The point $\mathrm{A}$ is a $(3,-1)$ point of $L(\mathbf{r})$, but the positive eigenvalue appears to have a much smaller absolute value than the negative one. Moreover, the comparison between Figures $6 \mathrm{~d}$ and 6e illustrates that the surfaces depicted for $[\mathrm{Pb}(\underline{\mathbf{L} 3})]^{2+}$ and $[\mathrm{Pb}(\underline{\mathbf{L} 4})]^{2+}$ are comparable, while the point $\mathrm{A}$ in the case of $[\mathrm{Pb}(\underline{\mathbf{L} 4})]^{2+}$ is a maximum of $L(\mathbf{r})$. For $[\mathrm{Pb}(\underline{\mathbf{L 2}})]^{2+}$, both eigenvalues appear to be very small and, once scaled as the four other ligands, the variations of $L(\mathbf{r})$ seem very low leading to an almost flat surface (Figure 6c). It appears disputable, on the sole basis of the nature of the CP A, to assess the presence or not of an active lone pair as the transition between an inactive (Figure 6b) and a weakly active lone pair (Figure 6f) is quite slow. 


\section{Conclusions}

A range of criteria have been reviewed and critically discussed to assess the stereochemical activity of the $6 \mathrm{~s}^{2}$ lone pair on $\mathrm{Pb}^{\mathrm{II}}$ once encapsulated inside the molecular cavity of the well-studied cyclenbased ligand DOTAM ( $\underline{\mathbf{L} 2})$. To that end, the comparison of the relevant structural, orbital, and electronic properties derived for a homologous series of macrocyclic complexes differing only by their ring size turned out to be the most useful approach. Two references were chosen, $[\mathrm{Pb}(\underline{\mathbf{L} \mathbf{1}})]^{2+}$ that possesses an inactive lone pair, and a fifth complex involving an open-chain tetraacetamide chelator, $[\mathrm{Pb}(\underline{\mathbf{L} 5})]^{2+}$, that evidences a developed stereochemically active lone pair.

To assess and compare the status of the lone pair on the $\mathrm{Pb}^{\mathrm{II}}$ cation, a range of indicators were computed, that originates from several theoretical methods such as geometrical, orbital or electron density analyses. The $[\mathrm{Pb}(\underline{\mathbf{L} 2})]^{2+}$ complex appears to be a compound just on the frontier and no definite answer should be given about the activity of the lone pair located on $\mathrm{Pb}^{\mathrm{II}}$ in that particular case. Indeed, structural indicators, when conclusive, are more in favor of the inactivity of the considered lone pair, while NBO- and ELF-based indicators are more in favor of its activity.

The first interpretation should be that our results highlight some limitations of the theoretical tools used in this study. Therefore, further studies on various systems with delicate localization of electrons should be useful to quantify the robustness of each indicator and, maybe, orient the development of new tools. A second interpretation should also be to reconsider in the future the possibility to extrapolate chemical concepts valid for the $1^{\text {st }}$ to $4^{\text {th }}$ row elements to heavier ones belonging to the $5^{\text {th }}$ and $6^{\text {th }}$ periods, to which $\mathrm{Pb}^{\text {II }}$ belongs to [48]. Indeed, the lone-pair concept within the VSEPR theory has proven to be of considerable value for understanding the structural features of $\mathrm{Pb}^{\mathrm{II}}$ complexes for coordination numbers lower than 6 or higher than 8 , but in between, the situation is much less predictable. It appears that $[\mathrm{Pb}(\underline{\mathbf{L 2}})]^{2+}$ is an extreme case, which is by far too subtle to be dealt, even with the sophisticated theoretical tools used herein. At the present time, we cannot settle this issues and more work is required in these two directions.

Notwithstanding, the following general conclusions can be drawn from the present investigation.

Firstly, the bonding between the studied ligands and the $\mathrm{Pb}^{\mathrm{II}}$ cation is very ionic. A good picture of these complexes should be to consider them as a cation caged in a ligand, which might interact with other surrounding species (for instance a second coordination shell): the presence or not of an electrophile (such as a proton carried by a water molecule) should enhance the development of the lone pair. The question of the activity of the lone pair of $\mathrm{Pb}^{\mathrm{II}}$ should therefore be too subtle to be answered simply by “yes” or “no” answer.

Secondly, most of the considered indicators evidenced progressive and smooth evolutions along the 
studied series of complexes, without showing a clear-cut break. Although $\underline{\mathbf{L} 3}$ and $\underline{\mathbf{L} 4}$ have no been synthesized yet, it is interesting to see that almost every parameter do not present a gap in properties. The use of cut-off values appears therefore as quite challenging when transposing them from one case to another.

Finally, the topology of the Laplacian of the electron density is an important criterion to consider, but it should be used with some cautions to avoid too rough conclusions. Indeed, a careful examination of the evolution along the series has shown that the presence or the absence of an extremum is not so meaningful if the eigenvalues of its Hessian are ignored. To that end, a sampling method and graphical representation has been introduced that enables to recover the progressive transition from a lone pair described by an almost purely spherical to a more and more hybridized orbital along the series of complexes. In order to extend the scope of this methodology, we are currently validating its transferability to other systems of interest to coordination chemists for which the localization of the lone pair on lead or other elements is either obvious or still in debate. 


\section{References}

1. Ohtaki H, Radnai T (1993) Structure and dynamics of hydrated ions. Chem Rev 93:11571204. doi: 10.1021/cr00019a014

2. Shimoni-Livny L, Glusker JP, Bock CW (1998) Lone Pair Functionality in Divalent Lead Compounds. Inorg Chem 37:1853-1867. doi: 10.1021/ic970909r

3. Van Severen M-C, Piquemal J-P, Parisel O (2009) Beyond holo/hemidirectionality in Pb(II) complexes: Can the valence lone pair be bisdirected? Chem Phys Lett 478:17-19. doi: 10.1016/j.cplett.2009.07.036

4. Christensen NE, Satpathy S, Pawlowska Z (1986) First-principles theory of tetrahedral bonding and crystal structure of lead. Phys Rev B 34:5977-5980. doi: 10.1103/PhysRevB.34.5977

5. Pyykko P (1988) Relativistic effects in structural chemistry. Chem Rev 88:563-594. doi: 10.1021/cr00085a006

6. Wander MCF, Clark AE (2008) Hydration Properties of Aqueous Pb(II) Ion. Inorg Chem 47:8233-8241. doi: 10.1021/ic800750g

7. Van Severen M-C, Ryde U, Parisel O, Piquemal J-P (2013) Understanding the Chemistry of Lead at a Molecular Level: The Pb(II) 6s6p Lone Pair Can Be Bisdirected in Proteins. J Chem Theory Comput 9:2416-2424. doi: 10.1021/ct300524v

8. Gourlaouen C, Gérard H, Parisel O (2006) Exploring the Hydration of $\mathrm{Pb}^{2+}$ : Ab Initio Studies and First-Principles Molecular Dynamics. Chem - Eur J 12:5024-5032. doi: 10.1002/chem.200600045

9. Gourlaouen C, Parisel O, Gérard H (2011) Revisiting the holo- and hemidirected structural transition within the $\left[\mathrm{Pb}(\mathrm{CO})_{\mathrm{n}}\right]^{2+}$ model series using first-principles Molecular Dynamics. Dalton Trans 40:11282. doi: 10.1039/c1dt10604j

10. Van Severen M-C, Gourlaouen C, Parisel O (2010) Application of the topological analysis of the electronic localization function to archetypical $\left[\mathrm{Pb}(\mathrm{II}) \mathrm{L}_{n}\right]^{\mathrm{p}}$ complexes: The bonding of $\mathrm{Pb}^{2+}$ revisited. J Comput Chem 31:185-194. doi: 10.1002/jcc.21309

11. Guilard R, Roux-Fouillet B, Lagrange G, Meyer M, Bucaille A (2001) Polyazacycloalkanes, Organometallic Complexes That Incorporate Them As Ligands And The Use Of Said Compounds In The Extraction Of Heavy Metals, PCT Application WO 2001/046202 A1.

12. Carlton L, Hancock RD, Maumela H, Wainwright KP (1994) Stability enhancement of heavymetal-macrocycle complexes via pendant amide coordination. J Chem Soc Chem Commun 1007-1008. doi: 10.1039/C39940001007

13. Olatunde AO, Dorazio SJ, Spernyak JA, Morrow JR (2012) The NiCEST Approach: Nickel(II) ParaCEST MRI Contrast Agents. J Am Chem Soc 134:18503-18505. doi: 10.1021/ja307909x

14. Olatunde AO, Bond CJ, Dorazio SJ, Cox JM, Benedict JB, Daddario MD, Spernyak JA, Morrow JR (2015) Six, Seven or Eight Coordinate $\mathrm{Fe}^{\mathrm{II}}, \mathrm{Co}^{\mathrm{II}}$ or $\mathrm{Ni}^{\mathrm{II}}$ Complexes of Amide- 
Appended Tetraazamacrocycles for ParaCEST Thermometry. Chem - Eur J 21:18290-18300. doi: 10.1002/chem.201503125

15. Martell AE, Motekaitis RJ, Clarke ET, Delgado R, Sun Y, Ma R (1996) Stability constants of metal complexes of macrocyclic ligands with pendant donor groups. Supramol Chem 6:353363. doi: 10.1080/10610279608032555

16. Nagata MKCT, Brauchle PS, Wang S, Briggs SK, Hong YS, Laorenza DW, Lee AG, Westmoreland TD (2016) Correlation of solid state and solution coordination numbers with infrared spectroscopy in five-, six-, and eight-coordinate transition metal complexes of DOTAM. Polyhedron 114:299-305. doi: 10.1016/j.poly.2015.12.035

17. Meyer M, Dahaoui-Gindrey V, Lecomte C, Guilard R (1998) Conformations and coordination schemes of carboxylate and carbamoyl derivatives of the tetraazamacrocycles cyclen and cyclam, and the relation to their protonation states. Coord Chem Rev 178-180:1313-1405. doi: 10.1016/S0010-8545(98)00169-6

18. Ranyuk E, Douaihy CM, Lemeune AB, Guilard R (2011) Preparation, characterization and photophysical properties of hybrid materials from rare earth complexes of phosphonatosubstituted DOTAM derivatives. New J Chem 35:1189. doi: 10.1039/c0nj00955e

19. Hancock RD, Reibenspies JH, Maumela H (2004) Structural Effects of the Lone Pair on Lead(II), and Parallels with the Coordination Geometry of Mercury(II). Does the Lone Pair on Lead(II) Form H-Bonds? Structures of the Lead(II) and Mercury(II) Complexes of the Pendant-Donor Macrocycle DOTAM (1,4,7,10-Tetrakis(carbamoylmethyl)-1,4,7,10tetraazacyclododecane). Inorg Chem 43:2981-2987. doi: 10.1021/ic030277a

20. Cuenot F, Meyer M, Espinosa E, Guilard R (2005) Synthesis, Characterization, and X-ray Crystal Structures of Cyclam Derivatives. 8. Thermodynamic and Kinetic Appraisal of Lead(II) Chelation by Octadentate Carbamoyl-Armed Macrocycles. Inorg Chem 44:78957910. doi: 10.1021/ic0508019

21. Cuenot F, Meyer M, Espinosa E, Bucaille A, Burgat R, Guilard R, Marichal-Westrich C (2008) New Insights into the Complexation of Lead(II) by 1,4,7,10-Tetrakis(carbamoylmethyl)1,4,7,10-tetraazacyclododecane (DOTAM): Structural, Thermodynamic, and Kinetic Studies. Eur J Inorg Chem 2008:267-283. doi: 10.1002/ejic.200700819

22. Goubert-Renaudin S, Moreau M, Despas C, Meyer M, Denat F, Lebeau B, Walcarius A (2009) Voltammetric Detection of Lead(II) Using Amide-Cyclam- Functionalized Silica-Modified Carbon Paste Electrodes. Electroanalysis 21:1731-1742. doi: 10.1002/elan.200904661

23. Cuenot F, Meyer M, Bucaille A, Guilard R (2005) A molecular approach to remove lead from drinking water. J Mol Liq 118:89-99. doi: 10.1016/j.molliq.2004.07.019

24. Maumela H, Hancock RD, Carlton L, Reibenspies JH, Wainwright KP (1995) The Amide Oxygen as a Donor Group. Metal Ion Complexing Properties of Tetra-N-acetamide Substituted Cyclen: A Crystallographic, NMR, Molecular Mechanics, and Thermodynamic Study. J Am Chem Soc 117:6698-6707. doi: 10.1021/ja00130a008

25. Nugent JW, Lee H-S, Reibenspies JH, Hancock RD (2015) Spectroscopic, structural, and thermodynamic aspects of the stereochemically active lone pair on lead(II): Structure of the lead(II) dota complex. Polyhedron 91:120-127. doi: 10.1016/j.poly.2015.02.033 
26. Claudio ES, Horst MA, Forde CE, Stern CL, Zart MK, Godwin HA (2000) ${ }^{207} \mathrm{~Pb}-{ }^{1} \mathrm{H}$ TwoDimensional NMR Spectroscopy: A Useful New Tool for Probing Lead(II) Coordination Chemistry. Inorg Chem 39:1391-1397. doi: 10.1021/ic9909431

27. Frisch MJ, Trucks GW, Schlegel HB, Scuseria GE, Robb MA, Cheeseman JR, Scalmani G, Barone V, Mennucci B, Petersson GA, Nakatsuji H, Caricato M, Li X, Hratchian HP, Izmaylov AF, Bloino J, Zheng G, Sonnenberg JL, Hada M, Ehara M, Toyota K, Fukuda R, Hasegawa J, Ishida M, Nakajima T, Honda Y, Kitao O, Nakai H, Vreven T, Montgomery Jr. JA, Peralta JE, Ogliaro F, Bearpark MJ, Heyd J, Brothers EN, Kudin KN, Staroverov VN, Kobayashi R, Normand J, Raghavachari K, Rendell AP, Burant JC, Iyengar SS, Tomasi J, Cossi M, Rega N, Millam NJ, Klene M, Knox JE, Cross JB, Bakken V, Adamo C, Jaramillo J, Gomperts R, Stratmann RE, Yazyev O, Austin AJ, Cammi R, Pomelli C, Ochterski JW, Martin RL, Morokuma K, Zakrzewski VG, Voth GA, Salvador P, Dannenberg JJ, Dapprich S, Daniels AD, Farkas Ö, Foresman JB, Ortiz JV, Cioslowski J, Fox DJ (2009) Gaussian 09 D.01. Gaussian, Inc., Wallingford, CT, USA

28. Perdew JP, Burke K, Ernzerhof M (1996) Generalized Gradient Approximation Made Simple. Phys Rev Lett 77:3865-3868. doi: 10.1103/PhysRevLett.77.3865

29. Adamo C, Barone V (1999) Toward reliable density functional methods without adjustable parameters: The PBE0 model. J Chem Phys 110:6158-6169. doi: 10.1063/1.478522

30. Metz B, Stoll H, Dolg M (2000) Small-core multiconfiguration-Dirac-Hartree-Fock-adjusted pseudopotentials for post-d main group elements: Application to $\mathrm{PbH}$ and $\mathrm{PbO}$. J Chem Phys 113:2563. doi: 10.1063/1.1305880

31. Krishnan R, Binkley JS, Seeger R, Pople JA (1980) Self-consistent molecular orbital methods. XX. A basis set for correlated wave functions. J Chem Phys 72:650. doi: 10.1063/1.438955

32. Tomasi J, Mennucci B, Cammi R (2005) Quantum Mechanical Continuum Solvation Models. Chem Rev 105:2999-3094. doi: 10.1021/cr9904009

33. Grimme S, Antony J, Ehrlich S, Krieg H (2010) A consistent and accurate ab initio parametrization of density functional dispersion correction (DFT-D) for the 94 elements $\mathrm{H}-\mathrm{Pu}$. J Chem Phys 132:154104. doi: 10.1063/1.3382344

34. Huzinaga S, Klobukowski M (1993) Well-tempered Gaussian basis sets for the calculation of matrix Hartree-Fock wavefunctions. Chem Phys Lett 212:260-264. doi: 10.1016/00092614(93)89323-A

35. Reed AE, Curtiss LA, Weinhold F (1988) Intermolecular interactions from a natural bond orbital, donor-acceptor viewpoint. Chem Rev 88:899-926. doi: 10.1021/cr00088a005

36. Keith TA (2014) AIMAll 14.06.21. TK Gristmill Software, Overland Park

37. Noury S, Krokidis X, Fuster F, Silvi B (1999) Computational tools for the electron localization function topological analysis. Comput Chem 23:597-604. doi: 10.1016/S00978485(99)00039-X

38. Barysz M, Sadlej AJ (2001) Two-component methods of relativistic quantum chemistry: from the Douglas-Kroll approximation to the exact two-component formalism. J Mol Struct THEOCHEM 573:181-200. doi: 10.1016/S0166-1280(01)00542-5 
39. Le Person A, Moncomble A, Cornard J-P (2014) The Complexation of $\mathrm{Al}^{\mathrm{III}}, \mathrm{Pb}^{\mathrm{II}}$, and $\mathrm{Cu}^{\mathrm{II}}$ Metal Ions by Esculetin: A Spectroscopic and Theoretical Approach. J Phys Chem A 118:2646-2655. doi: 10.1021/jp412291z

40. Bianchi R, Gervasio G, Marabello D (2000) Experimental Electron Density Analysis of $\mathrm{Mn}_{2}(\mathrm{CO})_{10}$ : Metal-Metal and Metal-Ligand Bond Characterization. Inorg Chem 39:23602366. doi: 10.1021/ic991316e

41. Ziółkowski M, Grabowski SJ, Leszczynski J (2006) Cooperativity in Hydrogen-Bonded Interactions: Ab Initio and “Atoms in Molecules” Analyses. J Phys Chem A 110:6514-6521. doi: 10.1021/jp060537k

42. Morell C, Grand A, Toro-Labbé A (2005) New Dual Descriptor for Chemical Reactivity. J Phys Chem A 109:205-212. doi: 10.1021/jp046577a

43. Perdew JP, Parr RG, Levy M, Balduz JL (1982) Density-Functional Theory for Fractional Particle Number: Derivative Discontinuities of the Energy. Phys Rev Lett 49:1691-1694. doi: 10.1103/PhysRevLett.49.1691

44. Becke AD, Edgecombe KE (1990) A simple measure of electron localization in atomic and molecular systems. J Chem Phys 92:5397. doi: 10.1063/1.458517

45. Causà M, D’Amore M, Garzillo C, Gentile F, Savin A (2013) The Bond Analysis Techniques (ELF and Maximum Probability Domains) Application to a Family of Models Relevant to BioInorganic Chemistry. In: Putz MV, Mingos DMP (eds) Appl. Density Funct. Theory Biol. Bioinorg. Chem. Springer Berlin Heidelberg, Berlin, Heidelberg, pp 119-141

46. Bader RFW, Gillespie RJ, MacDougall PJ (1988) A physical basis for the VSEPR model of molecular geometry. J Am Chem Soc 110:7329-7336. doi: 10.1021/ja00230a009

47. Popelier P (2000) On the full topology of the Laplacian of the electron density. Coord Chem Rev 197:169-189. doi: 10.1016/S0010-8545(99)00189-7

48. The authors thank one of the anonymous reviewer for raising that point which helped by the way to clarify their thoughts. 
Figure 1: Schematic representation of the three known environments for the $\mathrm{Pb}^{\mathrm{II}}$ cation: holodirected (a), hemidirected (b) and bisdirected (c).

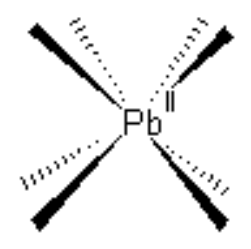

(a)

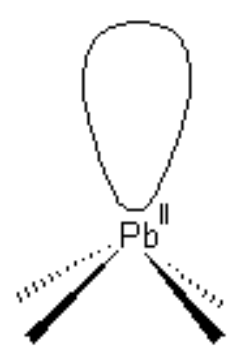

(b)

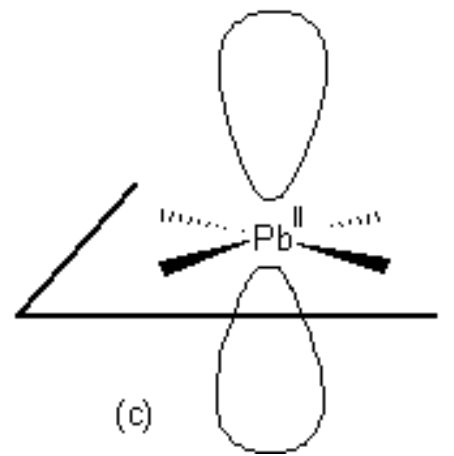


Figure 2: Structure of the five studied ligands.

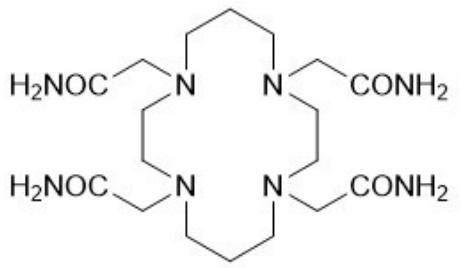

L1

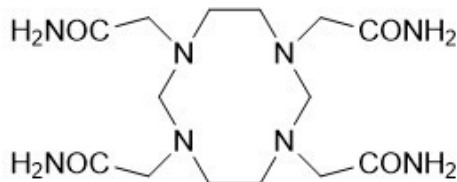

$\underline{\mathrm{L} 3}$

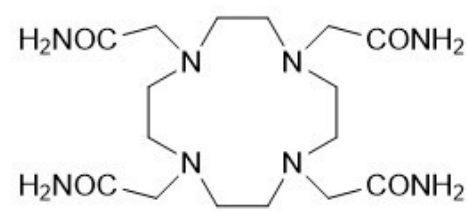

$\underline{\mathrm{L} 2}$

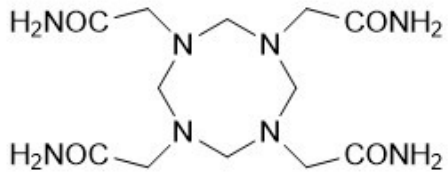

$\underline{\text { 노 }}$<smiles>NC(=O)CN(CCN(CC(N)=O)C(N)=O)CC(N)=O</smiles>

노 
Figure 3: DFT-optimized structure of the $[\mathrm{Pb}(\underline{\mathbf{L} 2})]^{2+}$ dication viewed (a) from the side and (b) down the $C_{4}$ rotation axis, and (c) schematic representation of three geometrical parameters reported in Table 1 and defined in the main text (for sake of clarity, the coordination sphere of $\mathrm{Pb}^{\mathrm{II}}$ is given as a cube that is not an exact representation).
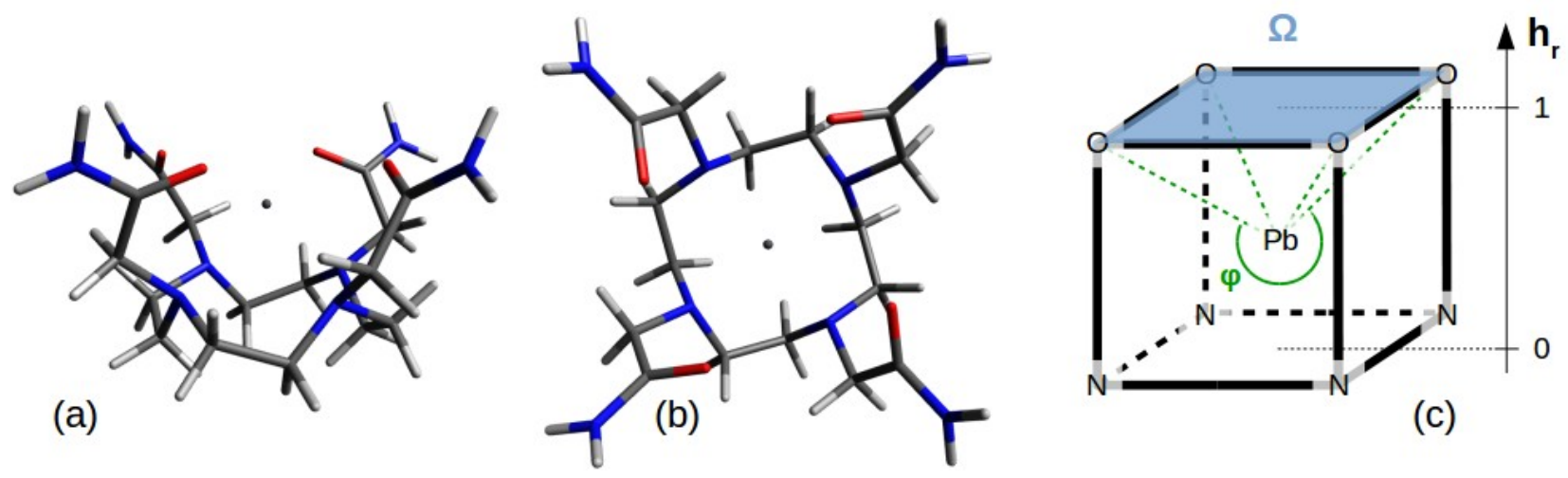

(c) 
Figure 4: Representation of the KS HOMO for (a) $[\mathrm{Pb}(\underline{\mathbf{L} 1})]^{2+}$, (b) $[\mathrm{Pb}(\underline{\mathbf{L} 2})]^{2+}$ and (c) $[\mathrm{Pb}(\underline{\mathbf{L} 5})]^{2+}$. The surfaces are depicted with a cut-off value of 0.05 a.u..
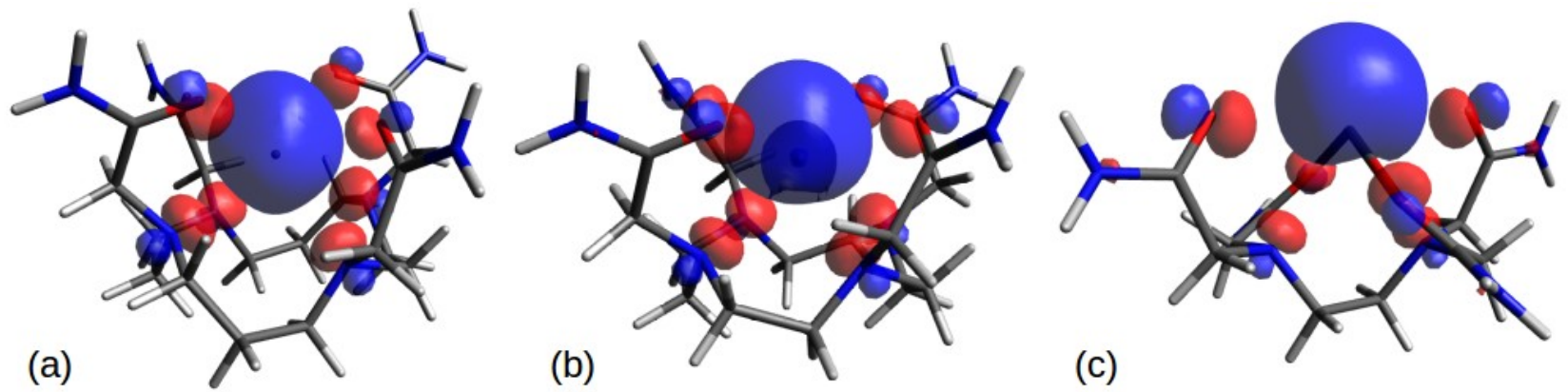
Figure 5: Location of the nine CPs considered for sampling the $L(\mathbf{r})$ function for $[\mathrm{Pb}(\underline{\mathbf{L} 4})]^{2+}$ along with the sampling presented in main text. Yellow: A $\left((3,-3)\right.$ in this case); green: $\mathrm{B}_{i}((3,-1)$ in this case); pink: $C_{i}((3,+1)$ in this case).

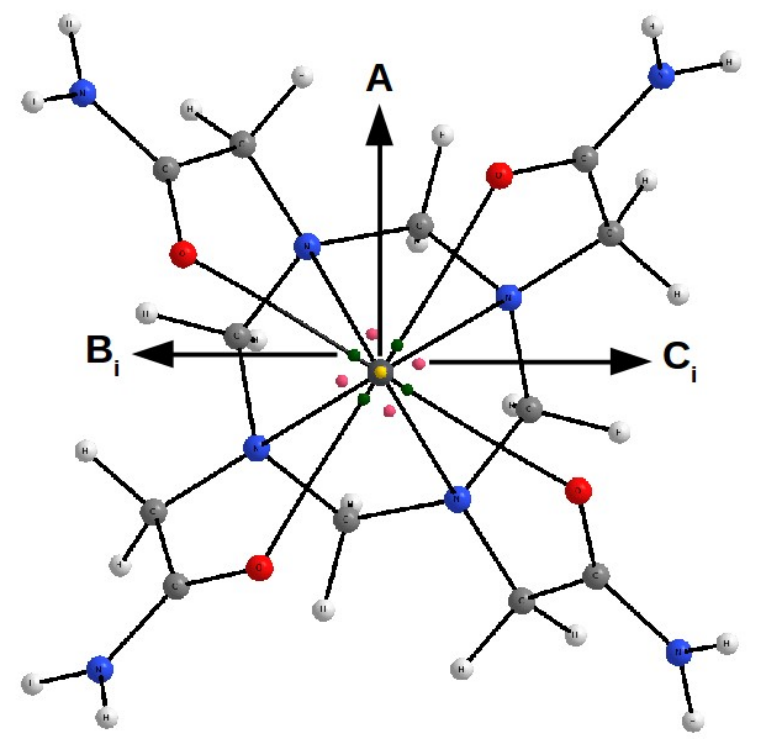


Figure 6: Position of the nine points used to sample $L(\mathbf{r})$ (a) and mesh representation of the interpolated $L(\mathbf{r})$ function sampled around the lone pair of the $\mathrm{Pb}^{\mathrm{II}}$ cation complexed by $\underline{\mathbf{L} \mathbf{1}}$ to $\underline{\mathbf{L} \mathbf{5}}$ ((b) to (f) respectively). See main text for more details.
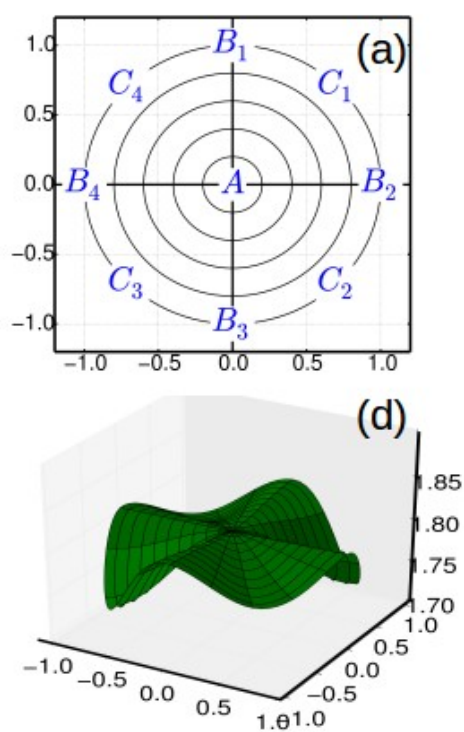

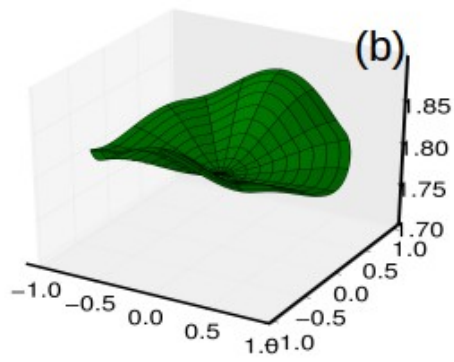

(e)

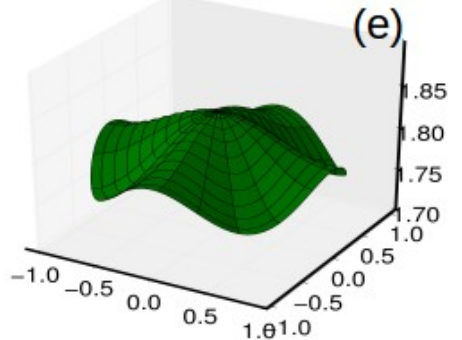

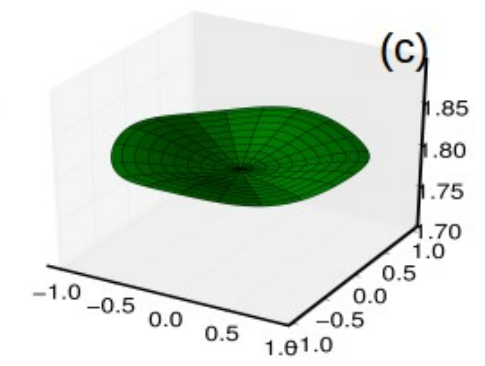

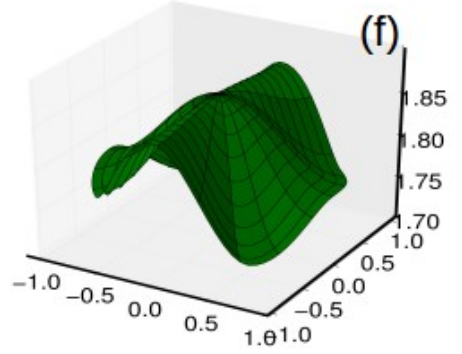


Table 1: Symmetry, $\mathrm{Pb}-\mathrm{O}$ and $\mathrm{Pb}-\mathrm{N}$ bond lengths, deviations of the $\mathrm{Pb}^{\mathrm{II}}$ cation from the binding $\mathrm{O}_{4}$ mean plane $\left(d_{\mathrm{O}}\right)$ and $\mathrm{N}_{4}$ mean plane $\left(d_{\mathrm{N}}\right), h_{\mathrm{r}}$ (relative height, see main text for the definition), mean bite angle $(\varphi)$ and solid angle under which the polygon defined by the four binding oxygens is seen from the $\mathrm{Pb}^{\mathrm{II}}$ cation $(\Omega)$ computed for the complex between $\mathrm{Pb}^{\mathrm{II}}$ and $\underline{\mathbf{L 1}}, \underline{\mathbf{L 2}}, \underline{\mathbf{L} 3}, \underline{\mathbf{L} 4}$, and $\underline{\mathbf{L 5}}$. Distances are given in $\AA$, angles in degrees, and solid angles in steradians. The reported bond lengths are the means of four values for $C_{4}$ symmetric complexes, and of two values for $C_{2}$ symmetric complexes (for which two values are then given). Crystallographic bond lengths are taken from references [23], [21], and [26] for $\underline{\mathbf{L} \mathbf{1}} \underline{\mathbf{L} \mathbf{2}}$, and $\underline{\mathbf{L} \mathbf{5}}$, respectively.

\begin{tabular}{|c|c|c|c|c|c|}
\hline Ligand & $\underline{\mathbf{L 1}}$ & $\underline{\mathbf{L 2}}$ & $\underline{\mathbf{L 3}}$ & $\underline{\mathbf{L 4}}$ & $\underline{\mathbf{L 5}}$ \\
\hline Symmetry & $C_{2}$ & $C_{4}$ & $C_{2}$ & $C_{4}$ & $C_{2}$ \\
\hline $\begin{array}{c}\text { Bond lengths } \\
\text { Pb-O }\end{array}$ & & & & & \\
computed & $2.693 / 2.658$ & 2.713 & $2.676 / 2.711$ & 2.686 & $2.463 / 2.625$ \\
X-ray & $2.61(6) / 2.72(2)$ & $2.71(7) / 2.81(2)$ & - & - & $2.44(1) / 2.64(5)$ \\
Pb-N & & & & & \\
computed & $2.809 / 2.733$ & 2.695 & $2.709 / 2.661$ & 2.688 & $2.656^{\mathrm{a}}$ \\
X-ray & $2.69(3)$ & $2.625(6)$ & - & - & $2.61(1)$ \\
& & & & & \\
Dist. to plane & & & & & \\
$d_{\mathrm{O}}$ & 1.163 & 0.915 & 0.565 & 0.240 & $-0.301^{\mathrm{b}}$ \\
$d_{\mathrm{N}}$ & 1.531 & 1.638 & 1.884 & 2.077 & $2.181^{\mathrm{a}}$ \\
$h_{\mathrm{r}}$ & 0.58 & 0.64 & 0.77 & 0.90 & $1.16^{\mathrm{a}, \mathrm{b}}$ \\
& & & & & \\
\hline Angles & & & & & \\
$\varphi$ (bite angle) & 232 & 219 & 204 & 190 & 0.58 \\
$\Omega /(4 \pi)$ & 0.24 & 0.29 & 0.37 & 0.46 & \\
\hline
\end{tabular}

${ }^{\mathrm{a}} \underline{\mathbf{L} 5}$ possesses only two binding nitrogen atoms. The $\mathrm{d}_{\mathrm{N}}$ distance is taken with respect to the $\mathrm{N} \cdots \mathrm{N}$ axis.

${ }^{\mathrm{b}}$ The negative $d_{\mathrm{O}}$ and higher than unity $h_{\mathrm{r}}$ values indicate that the lead center lies above the oxygen mean plane, while it is sandwich in-between the $\mathrm{N}_{4}$ and $\mathrm{O}_{4}$ mean planes in the four macrocyclic complexes. 
Table 2: NBO results: natural electron configuration of the $\mathrm{Pb}^{\mathrm{II}}$ cation, contribution of $\mathrm{p}$ orbitals (\%), orbital composition and occupancy of the lone pair (LP) on $\mathrm{Pb}^{\mathrm{II}}$ and of the three higher orbitals, and most important terms obtained from the second-order perturbation analysis between orbitals located on $\mathrm{Pb}^{\mathrm{II}}$ (stabilization energy $E^{(2)}$ in $\mathrm{kcal} \mathrm{mol}^{-1}$, orbitals energy difference $\Delta E$ in a.u. and the off-diagonal NBO Fock matrix element $F$ in a.u.).

\begin{tabular}{|c|c|c|c|c|c|}
\hline Ligand & $\underline{\mathbf{L 1}}$ & $\underline{\mathbf{L} 2}$ & $\underline{\mathrm{L} 3}$ & $\underline{\text { L4 }}$ & $\underline{\mathrm{L} 5}$ \\
\hline $\begin{array}{c}{[\mathrm{Pb}]} \\
\% \mathrm{p}\end{array}$ & $\begin{array}{c}(6 s)^{1.97}(6 p)^{0.53} \\
21.2\end{array}$ & $\begin{array}{c}(6 s)^{1.94}(6 p)^{0.62} \\
24.2\end{array}$ & $\begin{array}{c}(6 s)^{1.93}(6 p)^{0.63} \\
24.6\end{array}$ & $\begin{array}{c}(6 s)^{1.92}(6 p)^{0.61} \\
24.1\end{array}$ & $\begin{array}{c}(6 s)^{1.90}(6 p)^{0.59} \\
23.7\end{array}$ \\
\hline $\begin{array}{c}\text { Composition } \\
\text { LP Pb } \\
\% p \\
\text { occup. } \\
\text { LP Pb +1 } \\
\% p \\
\text { occup. } \\
\text { LP Pb +2 } \\
\% p \\
\text { occup. } \\
\text { LP Pb +3 } \\
\% p \\
\text { occup. }\end{array}$ & $\begin{array}{c}0.10 \\
1.976 \\
\\
100.00 \\
0.184 \\
100.00 \\
0.173 \\
99.90 \\
0.170\end{array}$ & $\begin{array}{c}1.78 \\
1.975 \\
\\
98.22 \\
0.224 \\
100.00 \\
0.180 \\
100.00 \\
0.180\end{array}$ & $\begin{array}{c}2.88 \\
1.979 \\
\\
97.12 \\
0.238 \\
100.00 \\
0.174 \\
100.00 \\
0.165\end{array}$ & $\begin{array}{c}3.37 \\
1.980 \\
\\
96.63 \\
0.222 \\
100.00 \\
0.163 \\
100.00 \\
0.163\end{array}$ & $\begin{array}{c}4.66 \\
1.980 \\
\\
95.34 \\
0.235 \\
100.00 \\
0.159 \\
100.00 \\
0.119\end{array}$ \\
\hline $\begin{array}{c}\text { Second order } \\
E^{(2)} \\
\Delta E \\
F\end{array}$ & $\begin{array}{c}0.56 \\
0.31 \\
0.012\end{array}$ & $\begin{array}{c}2.63 \\
0.30 \\
0.026\end{array}$ & $\begin{array}{c}3.55 \\
0.30 \\
0.031\end{array}$ & $\begin{array}{c}3.63 \\
0.30 \\
0.031\end{array}$ & $\begin{array}{c}4.60 \\
0.31 \\
0.035\end{array}$ \\
\hline
\end{tabular}


Table 3: AIM results: bond lengths $(\AA)$, electron density ( $\rho_{\mathrm{BCP}}$, in a.u.), laplacian of the electron density $\left(\nabla^{2} \rho_{\mathrm{BC}}\right.$, in a.u.), kinetic electronic energy density ( $G_{\mathrm{BCP}}$, in a.u.), total electronic energy density ( $H_{\mathrm{BCP}}$, in a.u.), potential electronic energy density ( $V_{\mathrm{BCP}}$, in a.u.), opposite of the ratio between $G$ and $V$ at the BCP, and delocalization indexes $(\delta)$ for $\mathrm{Pb}-\mathrm{O}$ and $\mathrm{Pb}-\mathrm{N}$ bonds. For $C_{2}$ -symmetric complexes, two values are reported owing to large differences between the bonds.

\begin{tabular}{|c|c|c|c|c|c|}
\hline Ligand & $\underline{\mathbf{L 1}}$ & $\underline{\mathbf{L 2}}$ & $\underline{\mathbf{L 3}}$ & $\underline{\mathbf{L 4}}$ & $\underline{\mathbf{L 5}}$ \\
\hline $\mathbf{P b}-\mathbf{O}$ & & & & & \\
& & & & & \\
length & $2.693 / 2.658$ & 2.713 & $2.676 / 2.711$ & 2.686 & $2.463 / 2.625$ \\
$\rho_{\mathrm{BCP}}$ & $0.029 / 0.032$ & 0.029 & $0.030 / 0.028$ & 0.029 & $0.042 / 0.032$ \\
$\nabla^{2} \rho_{\mathrm{BCP}}$ & $0.084 / 0.092$ & 0.080 & $0.088 / 0.080$ & 0.087 & $0.16 / 0.10$ \\
$G_{\mathrm{BCP}}$ & $0.0217 / 0.0239$ & 0.0209 & $0.0225 / 0.0208$ & 0.0223 & $0.0407 / 0.0259$ \\
$H_{\mathrm{BCP}}$ & $-0.0007 /-0.0010$ & -0.0008 & $-0.0007 /-0.0007$ & -0.0006 & $-0.0007 /-0.0007$ \\
$V_{\mathrm{BCP}}$ & $-0.0224 /-0.0249$ & -0.0217 & $-0.0233 /-0.0215$ & -0.0228 & $-0.0414 /-0.0270$ \\
$-G_{\mathrm{BCP}} / V_{\mathrm{BCP}}$ & $0.97 / 0.96$ & 0.96 & $0.97 / 0.97$ & 0.98 & $0.98 / 0.96$ \\
$\delta_{\mathrm{Pb}, \mathrm{O}}$ & $0.209 / 0.230$ & 0.213 & $0.223 / 0.219$ & 0.223 & $0.314 / 0.257$ \\
& & & & & \\
\hline $\mathbf{P b}-\mathbf{N}$ & & & & & \\
& & & & & \\
length & $2.809 / 2.733$ & 2.695 & $2.709 / 2.661$ & 2.688 & 2.656 \\
$\rho_{\mathrm{BCP}}$ & $0.030 / 0.034$ & 0.035 & $0.033 / 0.037$ & 0.034 & 0.368 \\
$\nabla^{2} \rho_{\mathrm{BCP}}$ & $0.063 / 0.077$ & 0.085 & $0.082 / 0.093$ & 0.088 & 0.095 \\
$G_{\mathrm{BCP}}$ & $0.0180 / 0.0219$ & 0.0240 & $0.0230 / 0.0264$ & 0.0246 & 0.0265 \\
$H_{\mathrm{BCP}}$ & $-0.0021 /-0.0027$ & -0.0028 & $-0.0025 /-0.0030$ & -0.0026 & -0.0027 \\
$V_{\mathrm{BCP}}$ & $-0.0201 /-0.0246$ & -0.0268 & $-0.0254 /-0.0293$ & -0.0272 & -0.0293 \\
$-G_{\mathrm{BCP}} / V_{\mathrm{BCP}}$ & $0.90 / 0.89$ & 0.90 & $0.91 / 0.90$ & 0.90 & 0.90 \\
$\delta_{\mathrm{Pb}, \mathrm{N}}$ & $0.226 / 0.250$ & 0.255 & $0.227 / 0.244$ & 0.214 & 0.252 \\
\hline
\end{tabular}


Table 4: NPA and AIM charges for $\mathrm{Pb}\left(q_{\mathrm{Pb}}\right)$, binding $\mathrm{O}\left(q_{\mathrm{O}}\right)$ and binding $\mathrm{N}\left(q_{\mathrm{N}}\right)$, condensed Fukui functions $\left(f_{\mathrm{Pb}}^{+}\right.$and $\left.f_{\mathrm{Pb}}\right)$ and dual descriptor $\left(f^{(2)}{ }_{\mathrm{Pb}}\right)$ for $\mathrm{Pb}$ calculated with these two schemes.

\begin{tabular}{|c|c|c|c|c|c|}
\hline Ligand & $\underline{\mathbf{L 1}}$ & $\underline{\mathbf{L 2}}$ & $\underline{\mathbf{L 3}}$ & $\underline{\mathbf{L 4}}$ & $\underline{\text { L5 }}$ \\
\hline $\mathbf{N P A}$ & & & & & \\
$q_{\mathrm{Pb}}$ & 1.50 & 1.44 & 1.45 & 1.48 & 1.51 \\
$q_{\mathrm{O}}$ & -0.71 & -0.70 & -0.70 & -0.70 & -0.72 \\
$q_{\mathrm{N}}$ & -0.59 & -0.60 & -0.61 & -0.61 & -0.60 \\
$f_{\mathrm{Pb}}^{+}$ & 0.55 & 0.50 & 0.48 & 0.47 & 0.69 \\
$f_{\mathrm{Pb}}$ & 0.35 & 0.42 & 0.45 & 0.47 & 0.55 \\
$f^{(2)}$ & 0.20 & 0.08 & 0.03 & 0.00 & 0.14 \\
& & & & & \\
\hline $\mathbf{P I M}$ & & & & & \\
$q_{\mathrm{Pb}}$ & 1.57 & 1.52 & 1.52 & 1.53 & 1.54 \\
$q_{\mathrm{O}}$ & -1.22 & -1.22 & -1.22 & -1.22 & -1.22 \\
$q_{\mathrm{N}}$ & -1.05 & -1.06 & -1.07 & -1.10 & -1.07 \\
$f_{\mathrm{Pb}}^{+}$ & 0.42 & 0.45 & 0.42 & 0.39 & 0.52 \\
$f_{\mathrm{Pb}}$ & 0.32 & 0.37 & 0.40 & 0.43 & 0.46 \\
$f^{(2)}$ & 0.10 & 0.08 & 0.02 & -0.04 & 0.08 \\
\hline
\end{tabular}


Table 5: Volume (in a.u.), population together with its standard deviation, and maximum value of ELF (in a.u.) for the monosynaptic basin located on $\mathrm{Pb}$ in its complexes with $\underline{\mathbf{L 1}}-\underline{\mathbf{L}} \mathbf{5}$.

\begin{tabular}{|c|c|c|c|c|c|}
\hline Ligand & $\underline{\mathbf{L 1}}$ & $\underline{\mathbf{L 2}}$ & $\underline{\mathbf{L 3}}$ & $\underline{\mathbf{L 4}}$ & $\underline{\underline{\mathbf{3}}}$ \\
\hline Volume & 36.13 & 103.38 & 128.30 & 141.25 & 179.67 \\
Population & 0.57 & 1.97 & 2.10 & 2.19 & 2.29 \\
Std. Deviation & 0.71 & 1.21 & 1.22 & 1.22 & 1.22 \\
Max ELF & 0.55 & 0.82 & 0.91 & 0.92 & 0.93 \\
\hline
\end{tabular}

